\begin{tabular}{c} 
journal homepage: http://ijiemjournal. uns.ac.rs/ \\
International Journal of Industrial \\
Engineering and Management \\
Volume $12 /$ No 4 / December $2021 / 243-252$ \\
\hline
\end{tabular}

Original research article

\title{
Implementation of the Single Minute Exchange of Dies method for reducing changeover time in a hygiene production company
}

\author{
M. Malindzakova ${ }^{\mathrm{a}}$, D. Malindzak ${ }^{\mathrm{b}}$ and P. Garaj ${ }^{\mathrm{a}}$ \\ a Technical University of Kosice, Institute of Logistics and Transport, Kosice, Slovakia; \\ ${ }^{b}$ U. S. Steel Kosice, Ltd., Kosice, Slovakia
}

\section{A B STR ACT}

This article focuses on implementing the Single Minute Exchange of Dies (SMED) method within the case study company, a local subsidy of a global producer of hygiene products. Such research was not yet done in the area of Eastern Slovakia, nor was it done for the area of hygiene produce production. The article lists unique specifics taken during the process. The results exceeded the preliminary management expectation, where a changeover time reduction by $30 \%$ was achieved. From the managerial perspective, this demonstrates that the SMED method is a mandatory approach for companies struggling with frequent and long changeover times.

\section{ARTICLE INFO}

Article history:

Received February 21, 2021

Revised July 19, 2021

Accepted August 2, 2021

Published online October 28, 2021

\author{
Keywords: \\ Lean management; \\ Single Minute Exchange of Dies \\ method; \\ changeover times; \\ streamlining processes \\ *Corresponding author: \\ Marcela Malindzakova \\ marcela.malindzakova@tuke.sk
}

\section{Introduction}

The current modern age is characterized by its variability and instability in the market environment. Considering the global technology shift and global competiveness, modern companies are constantly pressured to undergo organizational changes and technological investments that make factories smarter and more efficient [1]. Customers require short delivery times and high delivery reliability.

However, the wide range of customer demand creates contradictory goals for the company of increasing the variability of production whilst at the same time, the efforts must be made to minimize idle production times and maintain the fluency of production. This brings the focus on the changeover processes, where the company can either try and minimize the overall number of changeovers needed or shorten the actual changeover time. However, reduced variability of products inadvertently leads to customer dissatisfaction, leaving the possibility to shorten changeovers the most viable possibility [2]. Considering the losses in a company, changeover time of dies can be regarded as possibly the most significant non-value-added activity. Thus, reducing the changeover times directly translates into cost reduction [3]. 
The best way to overcome this problem is to produce a small lot size in the most economical and efficient way [4]. Through lean manufacturing principles, it is possible to increase productivity while maintaining ever lower costs [5]. This is to increase the efficiency of the production process by improving or even optimizing working processes. The principle of lean production is the elimination of any waste in the production process. Lean production is especially useful for productions producing various products with many production resetting and changeovers needed as opposed to large high-volume productions of standardized products with minimal product changeovers [6]. Lean manufacturing lists seven types of waste: overproduction, inventory, mistakes and quality defects, waiting, over-processing, unnecessary transport, and unnecessary movement [7]. In regard to time wastes, however, fast changeover time is the key to reducing large batch production [8]. If the changeover times are too long or complicated, the companies try to avoid changeovers which results in large batches. Besides limiting the operational flexibility, large production batches make it difficult to meet the customer's needs [9].

A typical changeover involves the preparation of equipment, replacement of tools, materials, and changes in the settings of production equipment related to the change of the type of product produced. These time wastes do not bring any additional added value that customers are willing to pay for. These specified reasons point to the need to reduce the duration of these activities carried out as part of the changeover process, which can be achieved by introducing a system of rapid change [10]. One of the tools used in the implementation of this system is the so-called SMED method. Radical reduction of duration from few hours down to few minutes can be achieved by gradual changes in the organization of the changeover process, standardization of equipment procedures, training and coaching of a team of operators, special aids, and technical modifications of the machines in question. It can be said that the time reduction programs such as SMED should be used wherever settings changes on machines are made frequently, and changeover times represent significant losses of machine or production line capacity. In such an operation, the need for the implementation of the SMED method is almost compulsory [11]. SMED method can help eliminate this kind of loss while increasing production capacity [12].

\section{Theoretical background}

The SMED method was developed by Shigeo Shingo, a Japanese industrial engineer, who said that it is "a scientific approach to reduce set-up time that can be applied in any factory to any machine" [13]. Agung \& Hasbullah [14] also suggest using the 5S technique to regulate workplaces to maintain quality while enhancing productivity. Alternatively, the Justin-Time lean tool has been suggested to be used in combination with the SMED method [15]. However, for this article, only the SMED method was considered.

The purpose of the SMED method is to considerably reduce the changeover times and streamline the processes of performing machine and facilities changeovers. The main principle of the method recommends performing as many changeover steps during the so-called external stage, which is the time period when the machine or the facility is running. At the same time, the remaining internal operations are simplified, standardized in order to eliminate any unnecessary operations, idle times, or wastes of other resources. The name SMED is an acronym of the term - Single Minute Exchange of Dies, which states the actual primary goal of the method of reducing the changeover times to times under ten minutes [16]. After a successful implementation of the SMED method, the production should achieve several benefits. The first one is the reduction of production costs, where the reduced changeover time translates into reduced downtimes which bring direct benefits from the reduced changeover [17].

The article deals with the reduction of the machine changeover / set-up time, which is defined as the time period running from the production of the last successfully completed product of a given production batch to the successful production of a first new product from a new production batch. This process usually involves partial machine dismantling, followed by machine resetting and concluded by machine reassembly. At the same time, the process includes the preparation times and other activities needed for the actual realization of the changeover [18].

The second benefit of implementing the SMED method for changeover processes is represented by smaller batch sizes in the production, as the shorter changeover times make the production much more flexible to change the product assortment.

This increased flexibility also improves the production schedule, which can respond more promptly to customer demands due to SMED implementation. As the production becomes more flexible, the 
required inventory amounts are reduced as the company can change to a new production batch more quickly. As time-to-market is gaining importance, the reduction of changeover times is one of the focal points to maintain competitiveness. In addition, in cases where the demand for a product is dropping, companies must take special care to reduce the amount of in-house stock amounts to remain flexible [19]. Abraham et al. [20] argued that the need for SMED is mandatory due to increased demand for variable products and reduced product life cycles. The SMED method implements standardization of changeover processes, which results in quality improvement thanks to consistency in the machine setting. Furthermore, the studies show that SMED implementation can significantly improve the ergonomics and working conditions for the operators working on the given machine by significantly reducing the distances walked by the operators during the changeover process with a total travel distance saving of up to $80 \%$ [21].

Within the framework of the SMED method, the individual changeover steps or operations are called elements. The SMED method recognizes two types of elements, namely so-called external elements, that can be worked on whilst the machine in question is running and the internal elements which can be worked on when the machine or facility is stopped. In general, during the implementation of the SMED method, the emphasis should be there to strive for more internal elements and streamline the necessary internal elements [22]. The SMED implementation team might even identify non-value-added activities that can be removed right away without negatively affecting the process [23]. However, the practical implementation of the SMED process stages must be proceeded by the creation of a SMED team that includes members from different departments, such as project engineers, process engineers, shift-leader, and selected setters and operators. Primarily all implementation team members must be briefed on the goal, and their responsibilities must be clearly defined [24]. Furthermore, training in SMED principles and goals is also a component that must be considered as, according to Karwasz \& Chabowski [25], building employee awareness is crucial for the success of the implementation. Educated and well-informed employees are able to perform SMED implementation activities more smoothly [26].

Before starting, the implementation team should have a clear understanding of the most significant time loss occurring and where the losses are mostly felt within the production process. This preliminary notion should, however, be backed by hard data. To do that, a proper performance analysis should take place. For that measurement of the Overall Equipment Effectiveness (OEE) or Six Big Losses consideration can be used [26]. It is recommended to analyze the OEE on the bottleneck machine or facility as the changeover time reduction directly translates into improved production performance and costs reduction [27]. At this stage, Value Stream Mapping might be used to provide a framework to start the process improvement through a systematic approach [28]. Subsequently, the recommended duration for a manufacturing performance measurement should last at least two weeks to collect sufficient data to achieve a clear overview of where the time losses indeed occur. The following section wishes to describe implementing the SMED method by highlighting the four elementary steps.

\subsection{Specify pilot area}

According to Antosz and Pacana [29], implementing SMED lies in the fact that companies often do not realize what effects shall be expected after implementing this method on different work facilities. This is especially the case for companies, which have just learned about this method. Based on the hard data analysis, the decision should be made, which machine or facility should be chosen for the initial pilot run of the SMED analysis. When choosing the analyzed process, two main criteria must be applied: the number of changeovers during a month and the time of the changeover [29]. First, it is the changeover duration, where for the pilot run, a process should be selected where there is an evident room for improvement, but on the other hand, the duration is not too long to discourage the implementation team by overwhelming it. Another factor is a variation in the changeover times, which might indicate that by implementing a standardized process, the changeover should be not only shorter but also consistent in duration. The next factor to be considered is the frequency of changeovers, where if the changeovers are more frequent, there is plenty of opportunities to test the implemented changes immediately. Yet another factor to consider is the familiarity with the given machine or facility for the implementation team and for the operators and other changeover staff, which makes the changes considerably more easy to implement. Last but not least, the production constraints of the equipment should be considered, and a sufficient amount of products should be prepared in advance to compensate for the losses during changeover changes testing. 
A necessary part of the process is to get the relevant employees on board to implement the changes successfully. Next, the baseline time must be set as a measurement of the time duration between the last good part produced before the changeover and the first good part produced after the changeover setting, both times recorded at full speed of the facility in question [30].

\subsection{Step one - Identify elements - Identification stage}

In the initial stage of the SMED method implementation, it is necessary to understand in detail the whole changeover process [31]. The changeover process usually involves the basic activities of Clean-Up, Set-up, Start-Up [32]. During this stage, it is necessary to review the process of performing a changeover and prepare a list of individual elements. Instead of disrupting the ongoing production, it is recommended to record a video of the changeover process and subsequently analyze and compile a list of individual steps along with the individual time durations [30]. To understand the changeover process better and identify potential problems, it is recommended to including the operators in an open dialogue [33].

It is recommended to capture the actions performed by the machine operator and the steps or the operations performed by the machine during the changeover. Usually, the actual optimization involves the actions performed by the operator [34]. It is also recommended to record the changeover without making any comments in order to capture the actual performance of the changeover. The availability of recording equipment makes it very easy to record and meticulously analyze the changeover process in order to identify unnecessary steps [35]. The final output of this stage should be a list of individual changeover steps along with time duration and description notes.

\subsection{Step two - Separate external elements - Separation stage}

During the second stage, the SMED implementation team identifies the elements that can be easily performed externally, which means, can be performed before or after the changeover whilst the machine or facility is running. Typical examples of such steps might include cleaning, inspections, quality checks, but meanly tools or material retrievals [30]. The output of this implementation stage is a list of elements, where several elements were identified as external, along with recommendations when these elements should take place, if it's before, during, or after the changeover [36].

\subsection{Step three - Convert internal elements to external - Transformation stage}

During the third step, the effort should be made to transform internal changeover processes into external ones. At the same time, each change should be carefully examined in regard to costs and labor needed for the change to be implemented, balanced against the benefits the time-saving the change will bring [34]. Each element within the changeover procedure should be looked at, and the most promising elements should be prioritized. This stage might involve the following activities [37]:

- Preparation, where the material, tools and machine parts are prepared well ahead of the changeover in order to substantially reduce time needed for the actual changeover or bulleted lists.

- Use of jigs and measuring templates to prepare alignments and settings adjustments before the changeover.

- Modification of the machine, so certain steps such as cleaning can be performed whilst the machine is running.

At the same time, such changes should be reviewed by safety experts and operators to make sure the changes reflect the occupational safety requirements to prevent potential injuries and safety accidents [38]. After completing this stage, the revised list of elements should include fewer internal elements but more external elements.

\subsection{Step four - Streamline remaining elements - Improvement Stage}

The last step involves streamlining and simplifying the remaining internal and external processes. In general, two broad areas of improvement should be recognized when trying to improve processes. First, those are the human aspects that can be improved by a better preparation and work organization level. On the other hand, there are improvements and streamlining of technical processes, which require engineering changes within the process [30].

Examples of human and technical elements that could be considered at this stage might include the following. To eliminate the bolts and screws and re- 
place them with technical solutions such as clams to shorten changeover time. To use color-coding for the changeover tools to avoid trial and error to find the right tool for the given activity [39]. Change traditional numerical adjustments to several pre-set settings and shims to standardize the size. Eliminate unnecessary movement by rearranging workspace. Eliminate unnecessary waiting by changing priorities. The last step usually involves mechanization and automation, replacing human interactions [40].

It should be noted that the changes in the human elements are much easier and cheaper to implement and, therefore should be focused on first. After concluding a SMED implementation, it is important to state that $\mathrm{SMED}$ is a process and not a one-off implementation program, and therefore companies should strive to continue sustaining and improvements through SMED in their processes [41]. a selected production line was analyzed considering the SMED method implementation, and the main assumption was made supported by the literature review. Although the research in the area of SMED method implementation was already examined, such analyses were not yet done in Eastern Slovakia, nor was done for the area hygiene product production used in this case study scenario.

Specification of problem areas within the production process

In the case study company within the scope of this article, only one production line was investigated. The production line produces four types of hygiene products at a speed of 1500 pcs.min-1, representing the maximum utilization of the line as stated in the line manual. The production management is aware that the capsule packaging facility represents the bottleneck of the production line. The packaging production line

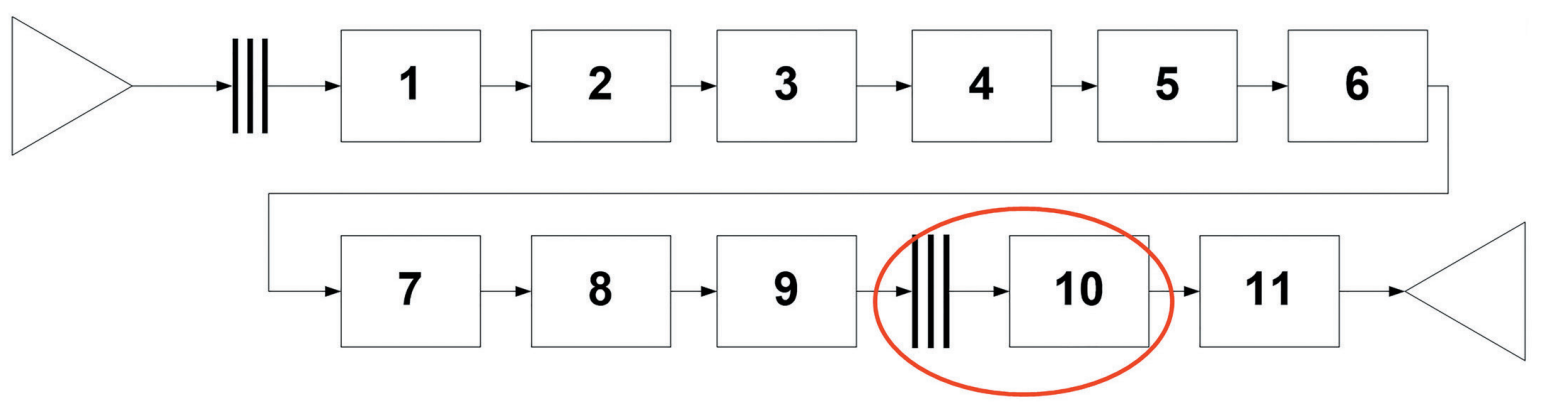

Figure 1. The production line producing hygiene products, including the identification of a bottleneck within the production process

\section{Research objective, methodology, and data}

For the purposes of this article, a case study method was implemented because of its use of solving problems in the area of the company's management decision-making [42]. Furthermore, the case study methodology was implemented as it enables the investigation of the cause and effect relationship in a real-life context. This is particularly suitable in this case as the point of the article was to demonstrate the effectiveness of the SMED method in real-life companies in order to test the proposed assumption.

The researched company is a local brand of a renowned global producer of hygiene products and, as such, understands the specific needs of its customers and transforms them into business goals. The products of the company help to improve and simplify the daily lives of hundreds of millions of people around the world. The company's products are distributed mainly to medical facilities, pharmacies, and other retailers.

Based on the initiative of the case study company, is fully automated, and a changeover is impossible without entirely stopping the production line. The changeovers are needed to reset the facility to a new product, as there are four different product variations being produced on the production line. Each product variation requires different size packaging capsules of different dimensions. As of right now, there is, on average, one changeover needed every three days on the packaging facility. This, in turn, represents a significant time loss of production time that directly translates into a financial loss for the company, not only due to the loss of the production but also due to the associated costs needed for the changeover setting.

The production process of female hygiene products begins by ordering basic raw materials using an in-company information system (Figure 1). Basic raw materials include cellulose, sheets of non-woven fabric (top-sheet), glue, a protective film (back-sheet), silicone paper, capsules, transport packaging (1). The cellulose is supplied in the form of rolls, from which it is moisturized (2), then follows to the mill, where the cellulose is ground (3). The ground cellulose is transferred to a molding facility (4) through 
a fan and pressed into the mold using a vacuum to create a core. Another non-woven fabric (top-sheet) enters, the adhesive is applied to the non-woven fabric, and is glued to the formed cellulose core (5). A small amount of perfume is used (6). Then the backsheet enters, on which glue is also applied and glued to the non-woven fabric and the core. The adhesive is applied to the back-sheet and glued to the other raw material with silicone paper (7). Subsequently, in the next part of the production line, the edges are compressed (8), and the products are cut into the final shape (9). The waste generated during cutting is sucked through a pipe to a processing site. The product stacking operation follows where, according to the type of product article (number of products in the package), the products are stacked into Lprofiles (10) and packed into capsules using cassettes (11). The capsules are marked with the production code using a laser. The marked products then pass through the weighing facility, and then the capsules are inserted into boxes using cassettes (12). The boxes with the final product are marked with the production code using a laser and moved to the finished product warehouse using conveyors (13).

\section{Results and Discussion}

\subsection{Case study - Step 1 - Identify elements - Identification stage}

Following identifying the bottleneck within production, the changeover process has been video recorded to properly analyze and identify every step and operation performed from the footage. Special care has been made to record a regular changeover operation with all the regular delays, flaws and insufficiencies included. A group of specialists was assembled in order to analyze the changeover process. Subsequently, the working team made a thorough list identifying each step performed during the changeover. Eventually, the team has compiled a list of 39 activities carried out during a changeover on the packaging facility. The list includes both the steps performed by the operator, but also the actions performed by the machine. Each changeover step duration was also properly measured to understand better where the time losses occur. The overall duration of one changeover takes on average 135 minutes. Thus the frequent changeovers can amount to up to 960 minutes (16 hours) a month. As the production runs $24 / 7$, the changeover time represents $2.15 \%$ of the total available production time. For this reason, applying the SMED method for this particular changeover process is highly suitable with the primary aim to reduce the time needed for the changeover.

\subsection{Case study - Step two - Separate external Elements - Separation stage}

Subsequently, the working group divided individual changeover steps into internal and external elements. As the first division into internal and external activities, the duration of internal activities was determined to be approximately 127 minutes, while the duration of external activities was 8 minutes. In terms of the number of elements, the internal elements represented 33 activities, and external elements represented six activities. Figure 2 presents the initial findings of the workgroup, determining that majority of the activities performed, namely $91 \%$ of the changeover time, were classified as internal elements, which means that these activities were performed whilst the production line is standing down. Only 9\% of the activities performed belong to external elements and were done while the production line was running. These activities represent the initial preparation processes, which were not done systematically by all operators as a rule. Within the SMED implementation, these preparation processes were changed into a production guideline to be followed. This means that the operators must order the necessary material from the warehouse and prepare the necessary tools well before the changeover starts. With minimal effort, it was also possible to optimize the preparation of the orders on a pc so that the operator can order the

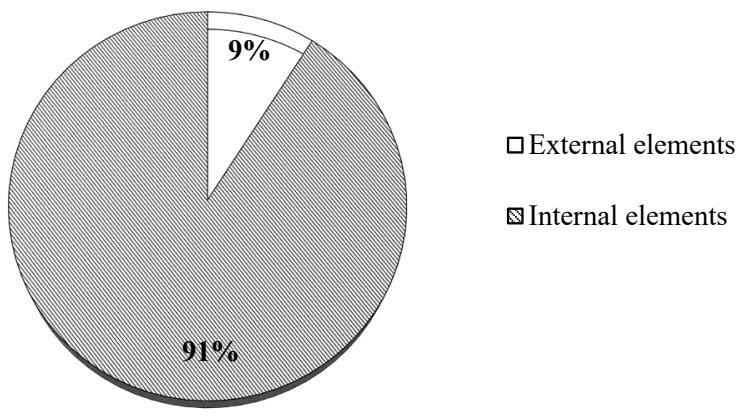

Figure 2. The division of changeover elements before the SMED implementation

material just in time before the planned changeover. A warehouse worker is responsible for the delivery of materials to the equipment. The application of these simple changes does not impose any additional costs for the company. 


\subsection{Case study - Step three - Convert internal elements to external - Transformation stage}

At this point, it is essential to highlight the operator's role, as his work activities and work performance directly influence the product output and the duration of the actual changeover time. The operator plays a significant role in maintaining the continuous operation of the line and the changeover of the facility. Thanks to the SMED analysis, several internal elements could be transferred into the external elements group (Figure 3). The following internal elements with the longest duration were considered:

- The discharge of the remaining products left in the line to the warehouse using a computer.

- Dry run of the system (stacker) to check that the program settings are correct.

- Preparation of pushers for injection of products into capsules.

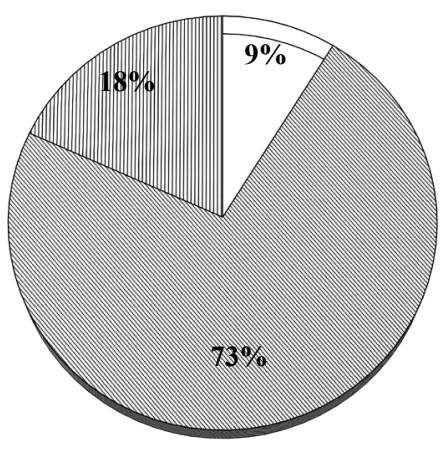

$\square$ External elements

Internal elements

๓ Transfer from internal to external elements

Figure 3. The duration of elements after conversion

\subsection{Case study - Step four - Streamline remaining elements - Improvement Stage}

Within this phase of SMED implementation, the aim is to simplify and streamline the existing processes. The working team of experts identified the following internal activities, which cannot be changed into external ones. Still, it can be significantly simplified and accelerated by implementing simple and inexpensive technological interventions. Figure 4 presents another group of activities, namely that of internal activities that can be accelerated. Here are examples of internal elements that could be streamlined:

- An operator opens the cover on the stacker, loosens the screws on the coupling, and sets the L-profiles according to the type of manu- factured article using a ruler. There are two couplings (3 screws on one coupling) and 40 x L-profiles.

- Replace two attachments on the discharge arms that push products into the L-profile.

- Replacements of pushers for injection of products into capsules (replacing screws).

- $\quad$ Checking the changeover settings using joysticks, so-called JOGs, to control the operation of the line manually.

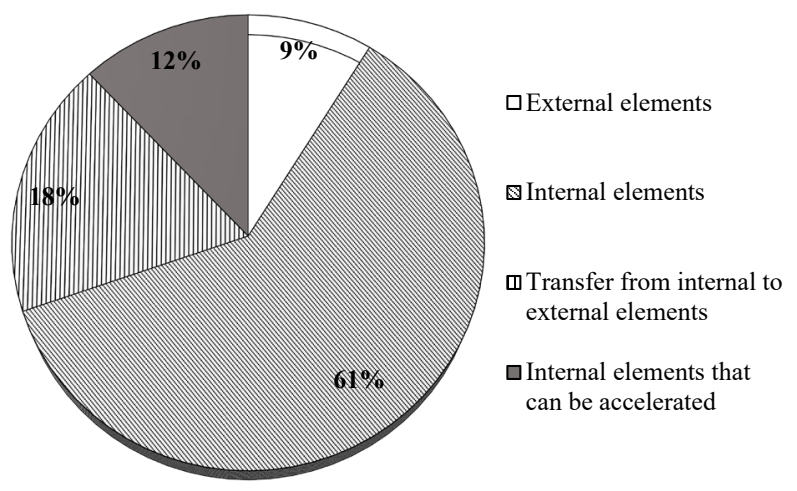

Figure 4. The duration of operations that are internal but can be streamlined

The proposed internal elements that could be streamlined represents $12 \%$ or the initial changeover time Figure 4.

To streamline and simplify the changeover, a recommendation was made to train another operator, as several activities during the changeover might be performed simultaneously. The task of this operator could be to perform another set of activities simultaneously during the changeover, including cleaning and maintenance of the equipment. Including a second operator can amount to an additional 15\% time saving (Figure 5). This change, however, did not take place yet. However, it is planned for future implementation when more frequent product changeovers are expected.

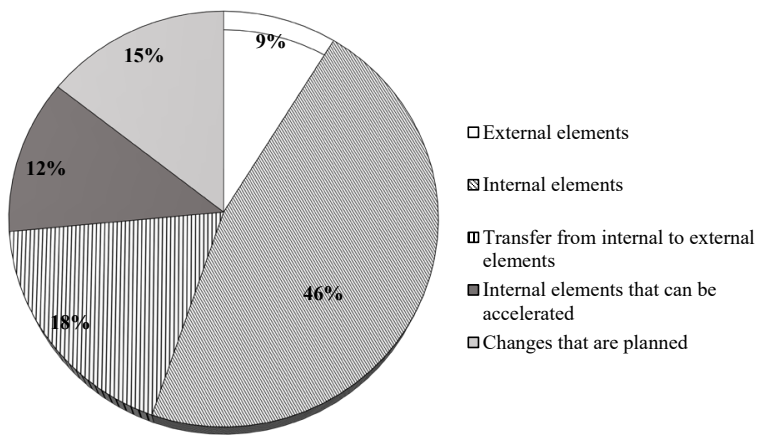

Figure 5. Proposed planned changes to the changeover elements in the future 


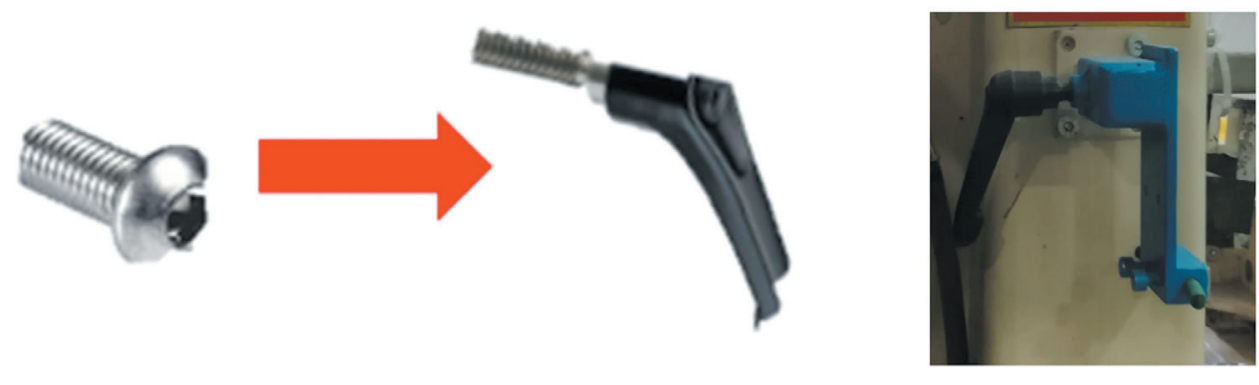

Figure 6. Replacement of classic screws with locking levers
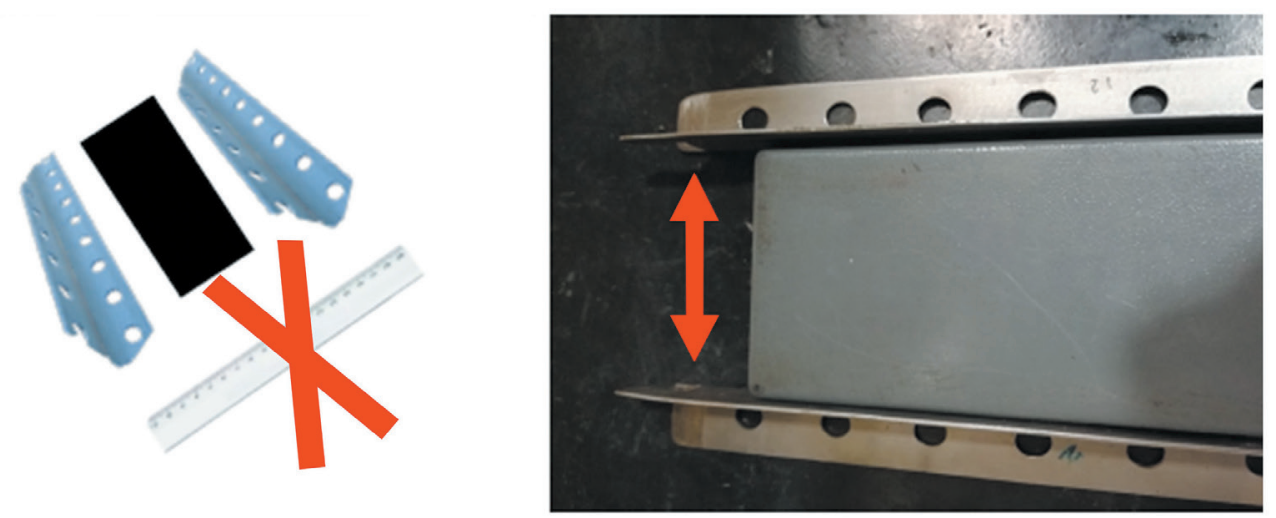

Figure 7. Creating a standard for the L-profile setting

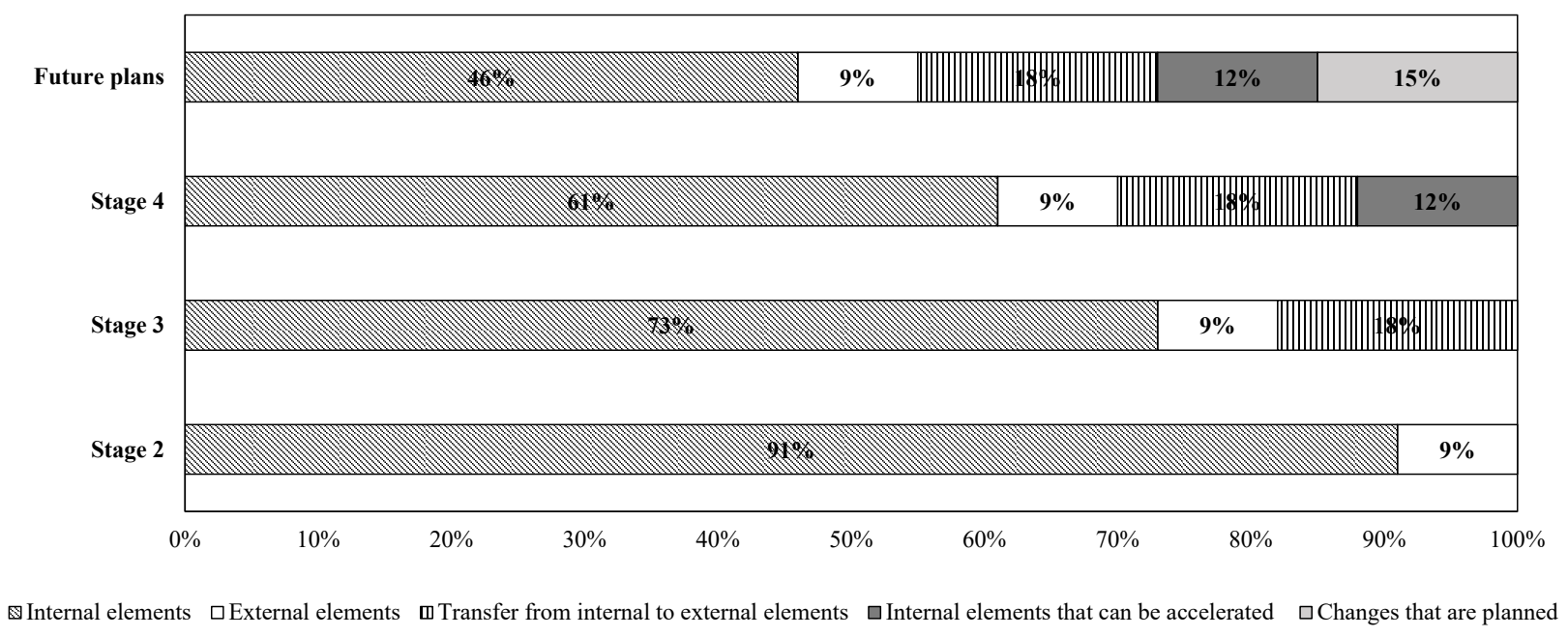

Figure 8. The SMED implementation stages in the case study company

The following section wishes to highlight some of the changes implemented to streamline the existing processes. One example implemented was reducing screw driving times by replacing the conventional screws with locking levers, significantly reducing the time needed (Figure 6).

For a faster set of guiding $\mathrm{L}$ - profiles, a standard measuring form was created. This measure made it possible to reset the L-profile without the traditional manual measurement (Figure 7).

\section{Conclusion}

By implementing the SMED method in the case study company, it was possible to reduce the changeover time by 76 minutes, representing a $30 \%$ reduction of the original changeover time. This reduction was possible by modifying 14 different steps of the changeover process (Figure 8). Considering the financial aspects, the case study company can save almost $2000 €$ per changeover. The SMED implementa- 
tion for the changeover process brought considerable time savings and significant savings on material.

From a management perspective, the changeover time reduction directly translates into increased production time and thus the production capacity. This not only confirms the preliminary assumption that implementation of the SMED method can save a significant portion of the changeover time but indeed demonstrates that as o tool, the SMED method is almost a mandatory approach for companies struggling with frequent and long changeover times. From the point of view of economic savings, it is possible to use the achieved time savings for the additional production of product articles, which means increasing the company's production capacity. The increase in the production capacity can be quantified through additional revenues generated from the sale. In conclusion, the implementation of the SMED method results in significant financial savings, shortening the changeover duration and simplifying existing operations.

\section{Funding}

This article was supported by the Slovak Cultural and Educational grant agency under the grant "Creating a modular system of synergic cooperation for sustainable development and corporate social responsibility" [grant agreement number KEGA 017TUKE-4/2019].

\section{References}

[1] N. Horňáková, L. Jurík, H. Hrablik Chovanová, D. Cagáňová, and D. Babčanová, "AHP method application in selection of appropriate material handling equipment in selected industrial enterprise," Wireless Networks, June 2019, doi: 10.1007/s11276-019-02050-2.

[2] L. Jurík, N. Horňáková, V. Domčeková, "The application of smed method in the industrial enterprise, " Acta Logistica, vol. 7, no. 4, pp. 269-281, 2020.

[3] R. Şahin, "A Case Study on Reducing Setup Time using SMED on a Turning Line, "Gazi University Journal of Science, April 2021, doi: 10.35378/gujs.735969

[4] S. Palanisamy, S. Siddiqui, "Changeover time reduction and productivity improvement by integrating conventional SMED method with implementation of MES for better production planning and control," International Journal of Innovative Research in Science, Engineering and Technology (IJIRSET), vol. 2, no. 12, pp. 7961-7974, 2013.

[5] M. Malindzakova, M. Mudry, "Management of chemical stocks by implementing statistical methods," Przemysł Chemiczny $=$ Chemical Industry, vol. 99, no. 5, pp. 780784, 2020, doi: 10.15199/62.2020.5.20.

[6] M. L. Mulla, S. G. Bhatwadekar, S. V. Pandit, "Implementation of Lean Manufacturing through the technique of Single Minute Exchange Oo Die (SMED) to reduce change Over time," International Journal of Innovative Research in Science, Engineering and Technology (IJIRSET), vol. 3, no. 6, pp. 13039-13076, 2014.

[7] D. Guzel, A. S. Asiabi, "Improvement set-up time by using SMED and 5S an application in SME," International Journal of Scientific \& Technology Research (IJSTR), vol. 9, no. 1, pp. 3727-3732, 2020.

[8] A. Winatie, B. P. Maharani, V. H. Riksa, S. Hasibuan, "Increasing time efficiency of change over process on solid product using SMED (Single Minute Exchange of Dies) method in pharmaceutical industry, "International Journal of Innovative Science and Research Technology, vol. 4, no. 6, pp. 639-644, 2019.

[9] E. Sousa, F. J. Silva, L. P. Ferreira, M. T. Pereira, R. Gouveia, R. P. Silva, "Applying SMED methodology in cork stoppers production, "Procedia Manufacturing, vol. 17, 2018, pp. 611-622.

[10] D. Zimon, T. Gajewska, M. Malindzakova, "Implementing the requirements of ISO 9001 and improvement logistics processes in SMES which operate in the textile industry," Autex Research Journal, vol. 18, no. 4, pp. 392-397, 2018, doi: 10.1515/aut-2018-0020.

[11] M. V. N. Pinjar, S. Shivakumar, G. V. Patil, "Productivity improvement through Single Minute Exchange of Die (SMED) technique, "International Journal of Scientific and Research Publications (IJSRP), vol. 5, no. 7, pp. 1-9, 2015.

[12] R. Assaf, T. Haddad, "An application of Single Minute Exchange of Die approach in an aluminium profiles extrusion production system: Case Study," International Journal of Scientific Research and Innovative Technology, vol. 4, no. 7, pp. 14-22, 2017.

[13] S. Shingo, "Quick changeover for operator: The SMED System, "Eds. New York, NY, USA: CRC Press, 2018, pp. $76-82$.

[14] D. Agung, H. Hasbullah, "Reducing the product changeover time using SMED \& $5 \mathrm{~S}$ methods in the injection molding industry, "SINERGI, vol. 23, no. 3, pp. 199-212, 2019.

[15] M. Konieczna, B. Mrugalska, M. K. Wyrwicka, "The application of Single Minute Exchange of Die in the production process improvement, "Logistics, vol. 3, no. 39, pp. 31-38, 2018, doi: 10.26411/83-1734-2015-3-39-7-18.

[16] V. Kumar, A. Bajaj, "The Implementation of Single Minute Exchange of Die with 5'S in Machining Processes for reduction of Setup Time, "International Journal on Recent Technologies in Mechanical and Electrical Engineering (IJRMEE), vol. 2, no. 2, 32-39, 2015.

[17] M. Wani, S. Risbud, S. Chaudhary, S. Gadgil, A. Bugade, "Reduction in engine changeover time using SMED methodology, "IJSRD - International Journal for Scientific Research \& Development, vol. 4, no. 1, pp. 514-517, 2016.

[18] S. Pellegrini, D. Shetty, L. Manzione, "Study and implementation of Single Minute Exchange of Die (SMED) methodology in a set-up reduction Kaizen," in Proceedings of the 2012 International Conference on Industrial Engineering and Operations Management, Istanbul, Turkey, 2012, pp. 2353-2363.

[19] A. C. Moreira, P. M. T. Garcez, Implementation of the Single Minute Exchange of Die (SMED) methodology in small to medium-sized enterprises: A Portuguese case study, "International Journal of Management, vol. 30, no. 1, pp. 66-87, 2013.

[20] A. Abraham, K. N. Ganapathi, K. Motwani, "Set-up time reduction through SMED technique in a stamping production line, "SASTech Journal, vol. 11, no. 2, pp. 47-52, 2012.

[21] D. Ribeiro, "An application of the SMED Methodology in an electric power controls company, "Proceedings of International Conference On Innovations, Recent Trends and Challenges in Mechatronics, MECAHITECH'11, Bucha- 
rest, Romania, 2011, pp. 47-55.

[22] B. Strickland, "Quick Changeover for Operators: The SMED System, "Journal of Manufacturing Systems, vol. 16, no. 3, pp. 233-234, 1997.

[23] D. Maurya, Y. Yadav, D. Pandey, "Change Over time reduction using SMED: An industrial case study, "International Journal of Scientific \& Engineering Research (IJSER), vol. 9, no. 3, pp. 13-17, 2018.

[24] P. Balon, J. Buchtova, "The SMED system - case study in the metal working industry," in METAL Conference, 25th Anniversary International Conference on Metallurgy and Materials, Brno, Czech Republic, 2016, pp. 1736-1741.

[25] A. Karwasz, P. Chabowski, "Productivity increase through reduced changeover time, "Journal of Machine Engineering, vol. 16, no. 2, pp. 61-70, 2016.

[26] R. Natholia, H. K. Gupta, P. Mishra, Y. Mishra, "Study of SMED methodology and its systematic procedure of implementation, "International Journal of Interdisciplinary Research, vol. 3, no. 1, pp. 1-5, 2017.

[27] I. Pawłyszyn, A. Stachowiak, Ł. Hadaś, "Application of SMED methodology in a printing-house, "Journal Research in Logistics \& Production, vol. 4, no. 4, pp. 357-368, 2014.

[28] M. M. Maalouf, M. Zaduminska, "A case study of VSM and SMED in the food processing industry, "Management and Production Engineering Review, vol. 10, no. 2, pp. 60-68, 2019.

[29] K. Antosz, A. Pacana, "Comparative analysis of the implementation of the SMED method on selected production stands, "Technical Gazette, vol. 25, no. 2, pp. 276-282, 2018, doi: 10.17559/TV-20160411095705.

[30] "SMED - Metoda zkracování času pretypování výrobných zarízení.” [Online]. Available: https://www.qmprofi.cz/33/ smed-metoda-zkracovani-casu-pretypovanivyrobnich-zarizeni-uniqueidgOkE4NvrWuOKaQDKuox_Z1RtTEX$\operatorname{maxdI9s-4764yV7U/.~[Accessed:~18-June-2020].~}$

[31] E. Costa, S. Bragança, R. Sousa, A. Alves, "Benefits from a SMED application in a punching machine, "International Journal of Industrial and Manufacturing Engineering, vol. 7, no. 5, pp. 951-957, 2013.

[32] D. Kumaravel, R. S. Bharathi, M. Kavinandini, "Enhancing the production through SMED methodology, "International Journal of Engineering \& Technology (IJET), vol. 7, no. 2.8, pp. 382-385, 2018.

[33] E. Otero, I. Lopes, "Productivity improvement of a production line through Quick Changeover Concept - A Case Study, "Advances in Transdisciplinary Engineering, vol. 7, pp. 897-906, 2018, doi: 10.3233/978-1-61499-898-3-897.

[34] J. R. Díaz-Reza, J. L. García-Alcaraz, J. R. Mendoza-Fong, V. Martínez-Loya, E. J. Macías, J. Blanco-Fernández, "Interrelations among SMED Stages: A Causal Model,“ Complexity, 2017, pp. 1-10, 2017, doi: 10.1155/2017/5912940.

[35] P. G. Ferradás, K. Salonitis, "Improving changeover time: A tailored SMED approach for welding cells, "in Proceedings of the 46th CIRP Conference on Manufacturing Systems, CIRPCMS, Setubal, Portugal, 2013, pp. 598-603.

[36] P. C. Kulkarni, G. Lahiri, "Improving productivity using SMED, "International Journal of Innovative Technology and Exploring Engineering (IJITEE), vol. 9, no. 3, pp. 1889-1892, 2020, doi: 10.35940/ijitee.B6319.019320.

[37] S. Kulkarni, "Reducing Change-over time using SMED process in automotive wheel rim manufacturing industry, "International Journal of Scientific Research and Engineering Development (IJSRED), vol. 2, no. 6, pp. 822-827, 2019.

[38] R. Sundar, A. N. Balaji, R. M. Satheesh Kumar, "A review on lean manufacturing implementation techniques, "in Proceedings of the 12th Global Congress on Manufacturing and Management, GCMM 2014, Vellore, India, 2014, pp. $1875-1885$.
[39] S. Shinde, S. Jahagirdar, S. Shriram Sane, V. Karandikar, "Set-up time reduction of a manufacturing line using SMED technique, "International Journal of Advance Industrial Engineering, vol. 2, no. 2, pp. 50-53, 2014.

[40] Y. R. Mali, K. H. Inamdar, "Changeover time reduction using SMED technique of lean manufacturing, "International Journal of Engineering Research and Applications, vol. 2, no. 3, pp. 2441-2445, 2012.

[41] M. Kuczyńska-Chałada, Implementation of the SMED method in a production enterprise, "in International Conference Multidisciplinary Aspects of Production Engineering MAPE, Serock, Poland, 2019, pp. 224-233.

[42] T. Bidarra, R. Godina, J. C. O. Matias, S. G. Azevedo, "SMED methodology implementation in an automotive industry using a case study method," Int. J. Ind. Eng. Manag., vol. 9, no. 1, pp. 1-16, 2018. 